\title{
An overall genetic risk assessment for radiological protection purposes
}

\author{
PER OFTEDAL AND A G SEARLE \\ From the Institute of General Genetics, University of Oslo; and the MRC Radiobiology Unit, Harwell, Oxon.
}

SUMMARY Risks of serious hereditary damage in the first and second generations after low level radiation exposure and at equilibrium were calculated by using a doubling dose of 100 rem (based on experimental work with the mouse) and by considering separately the various categories of genic and chromosomal defect. Prenatal lethality has not been included. It is estimated that after the exposure of a population of future parents to a collective dose of 1 million man-rem, about 125 extra cases of serious genetic ill health would appear in children and grandchildren. In all future generations, a total of about 320 cases is expected, provided the population remains of constant size. It is emphasised, however, that a number of major assumptions have to be made in order to arrive at any overall genetic risk estimate, so that the confidence limits of these figures are bound to be wide.

\begin{abstract}
Although various attempts have been made to evaluate the magnitude of human genetic risk from ionising radiation, most of these assessments have been incomplete. Figures have been given for some categories of risks but others have been omitted because of lack of evidence. Moreover, little attention has been paid to the severity of these risks compared with those resulting from the somatic effects of radiation. For the preparation of the new recommendations of the International Commission on Radiological Protection ${ }^{1}$ it was essential to put somatic and genetic risk assessments on a factual and a comparable basis as far as possible. Therefore a Task Group* was convened early in 1976 under the aegis of the ICRP to try and reach agreement on the extent to which the frequencies of the different components of human genetic ill health would be increased by low level irradiation and to express its findings in terms comparable with those for somatic risks. The substance of its report, submitted in late 1976 , is outlined in this paper, with some additional documentation. It concluded that about 125 extra cases of serious genetic ill health would be expected in the first two generations after a parental exposure of 1 million man-rem, and about 320 cases if all future generations were included.
\end{abstract}

*P Oftedal (Oslo, Chairman), C O Carter (London), U H Ehling (Munich), B K Trimble (Vancouver, deceased), $F$ Vogel (Heidelberg). Corresponding members were $\mathrm{J} \mathrm{H}$ Edwards (Birmingham), J V Neel (Ann Arbor), and A G Searle (Harwell).

Received for publication 14 May 1979

\section{Method of risk assessment}

As discussed in UNSCEAR ${ }^{2}$ there are two main methods of risk assessment, namely the direct method and the indirect or doubling dose method. The latter was preferred for present purposes because (1) it allows the risk to be expressed in terms of basic human hereditary damage, and (2) if an overall doubling dose is accepted, it allows an overall genetic risk assessment to be made even in the absence of direct experimental evidence on certain categories of hereditary defect. A doubling dose of $100 \mathrm{rad}$ was used for low LET irradiation at low doses and low dose rates in line with previous findings based on work with mice. ${ }^{3}{ }^{4}$ It was thought to be applicable to both male and female germ cells. Thus 1 rad of low LET irradiation (that is $1 \mathrm{rem}$ or $10 \mathrm{mSv}$ ) would be expected to increase the mutation frequency by $1 \%$. This is on the assumption of linear dose-response relationships, for which there is strong evidence for both mutations and chromosome damage in spermatogonia of mice with chronic exposures. ${ }^{56}$ Recently, Evans et $a l^{7}$ showed that the linearity principle holds for unbalanced chromosome aberrations in human lymphocytes even in the dose range 0 to 30 rem.

If $1 \mathrm{rem}$ increases the mutation frequency by $1 \%$, a parental dose of 1 rem would lead to a total increase of mutationally maintained deleterious conditions by $1 \%$. Some of these cases will be expressed only over the following several generations, making the 
increase in the first generation of children smaller than $1 \%$. However, if exposure continued at $1 \mathrm{rem}$ per generation, an equilibrium of $1 \%$ increase in each generation would be established with time.

Since these genetic risk estimates were to be compared with somatic risk estimates based mainly on cancer deaths, it was decided to consider the frequencies of only those hereditary conditions which had severe effects, such as congenital malformations and crippling disease. Intrauterine death was not regarded as a severe manifestation from this point of view.

\section{Calculations for chromosomal diseases}

The chromosomal conditions which add most to the human genetic load are thought to be the unbalanced products of translocations (both reciprocal and Robertsonian) and the various types of aneuploids which survive to birth, such as Down's syndrome (trisomy for chromosome 21), Klinefelter's syndrome (XXY), and Turner's syndrome (XO). It is known that reciprocal translocations can be induced by irradiation of both male and female germ cells, but the evidence is less good for Robertsonian (whole arm) translocations. ${ }^{8}$ The trisomic conditions arise by a process of non-disjunction, which is known to be increased by irradiation in various species including mice. The monosomic conditions may arise by non-disjunction or by chromosome loss, the latter also being inducible by radiation. ${ }^{9}$ However, only the XO condition may survive to birth.

\section{TRANSLOCATIONS}

The doubling dose method is not used for these, as some direct evidence is available from acute $x$ irradiation of human testes. Brewen et $\mathrm{al}^{10}$ estimated the rate of induction of balanced reciprocal translocations in spermatogonial stem cells of man and marmosets to be $7 \cdot 7 \times 10^{-4}$ per rad, with doses of up to $100 \mathrm{rad}$. A lower mutation rate would be expected at lower doses and at low dose rates. Thus, Searle $e t \mathbf{a l}^{11}$ found that the translocation frequency was halved after spermatogonial irradiation of mice with $300 \mathrm{rad}$ when the dose rate was lowered from $90 \mathrm{rad} / \mathrm{min}$ to $0.09 \mathrm{rad} / \mathrm{min}$. However, the reduction factor was $0 \cdot 1$ when acute doses of $600 \mathrm{rad} x$-rays were compared with the same $\gamma$-ray dose at 0.02 $\mathrm{rad} / \mathrm{min} .{ }^{12}$ A reduction factor of 0.5 for protraction of dose was used in the present calculations, bearing in mind that the human $x$-ray doses were below $100 \mathrm{rad}$.

If the frequency of balanced translocations in spermatocytes is $p$, the expected frequency in resultant gametes is $p / 4$ for balanced and $p / 2$ for unbalanced translocations. Ford et al $^{13}$ found that after a large fractionated $x$-ray dose to mouse $\stackrel{\mathbb{D}}{?}$ spermatogonia, the actual transmission of trans- $\overrightarrow{\vec{B}}$ locations was only half that expected. It is not yet clear, however, whether this reduced transmission is a general phenomenon in mammals, so the expected frequencies shown above have been used.

From the above considerations the rate of induction of unbalanced translocations in the gametes of $\%$ those exposed was estimated as $7.7 \times 10^{-4} \times 0.5 \overrightarrow{0}$ (protraction) $\times 0.5$ (transmission) per rad, which is $193 \times 10^{-6}$, leading to double this frequency in $\vec{\omega}$ resultant zygotes. Most of these zygotes would die in early embryonic life because of their chromosomal imbalance but it has been calculated ${ }^{14}$ that about $6 \% \overrightarrow{\vec{V}}$ would survive to birth with severe congenital malformations. Thus, the expected frequency of these $\vec{G}$ would be about 23 per million in the offspring of a man receiving one rad. The viable subjects inheriting $\frac{5}{5}$ induced balanced translocations (frequency 193 per $\vec{T}$ million) would produce offspring of which half $\mathbb{D}$ would be chromosomally unbalanced. If the factor of $6 \%$ is applied again, it can be seen that about 6 per million congenitally malformed liveborn would be expected in the second generation from a man receiving one rad. The contribution in later generations is small. Therefore, the equilibrium value for exposed males can be taken as 30 , with 23 cases in the first generation and 6 in the second.

Heritable translocations can be induced in female $\stackrel{0}{\circ}$ mice after $x$-irradiation of dictyate oocytes. ${ }^{1516} \mathbb{\perp}$ Although mutation rates are similar to those after $\overrightarrow{\vec{B}}$ spermatogonial irradiation, it seems probable from the results of specific locus experiments ${ }^{17}$ that the effect of lowering the dose rate will be more pronounced in oocytes than in spermatogonia. On the other hand, because translocations induced in 6 oocytes would be in the form of chromatid exchange, $\dot{0}$ a gamete from an affected oocyte would be six times more likely to have an unbalanced form of the $\delta$ translocation than a balanced one..$^{18}$ It seems reasonable to regard these opposing factors as cancelling 은 each other out. Therefore, risks from translocation $\rightarrow$ induction in female germ cells have been taken to be similar to those in male ones, and the values given in the previous paragraph have been used for both of sexes (table).

TRISOMIES AND THE XO CONDITION The overall frequency of sex chromosomal and autosomal trisomies and of the $\mathrm{XO}$ condition was considered to be $0.5 \%$ among newborn infants. A frequency of $0.36 \%$ was obtained from a series of $T$ chromosomal surveys. ${ }^{2}$ Experimental data suggest $\bar{O}$ that the frequency of transmission of aneuploid conditions is much lower after treatment of spermatogonia than of oocytes ${ }^{1920}$; therefore a correction 
TABLE Estimate of the number of cases of serious genetic ill health in offspring (excluding abortions) from parents irradiated with 1 million man-rem in a population of constant size.

\begin{tabular}{lcc}
\hline Category of genetic effect & Equilibrium & $1+2$ generation \\
\hline 1 Unbalanced translocations: risk of & 30 & $23+6=29$ \\
$\begin{array}{l}\text { malformed liveborn } \\
\text { Trisomics and XO }\end{array}$ & 30 & $30+0=30$ \\
$3 \begin{array}{l}\text { Simple dominants and sex-linked } \\
\text { mutations }\end{array}$ & 100 & $20+16=36$ \\
$\begin{array}{l}\text { Doninants of incomplete } \\
\text { penetrance and multifactorial } \\
\text { disease maintained by mutation }\end{array}$ & 160 & $16+14=30$ \\
5 Multifactorial disease not \\
$\begin{array}{l}\text { maintained by mutation } \\
6 \text { Recessive disease }\end{array}$ & 0 & 0 \\
\begin{tabular}{l} 
Total \\
\hline
\end{tabular} & 320 & $-89+36=125$ \\
\hline
\end{tabular}

factor of 0.6 was introduced. Since all these aneuploid conditions will be manifest in the first generation and will not reproduce, the expected frequency of extra cases for a doubling dose of 100 rem will be $0.005 \times$ $0.6 \times 0.01$ per rem, which is a risk of 30 per million in the offspring of a person receiving 1 rem (table).

\section{Calculations for genic diseases}

These diseases will comprise dominant and recessive as well as multifactorial conditions. An unknown fraction of these will be caused by small chromosomal deficiencies, behaving similarly to gene mutations.

For radiation protection purposes, interest will be limited to those conditions the population frequencies of which are maintained by mutation rather than by selective forces. For these and other reasons, it was considered essential to treat separately the following categories: (1) simple dominants and sex-linked conditions; (2) dominants of incomplete penetrance; (3) multifactorial conditions; and (4) recessives.

\section{SIMPLE DOMINANT AND SEX-LINKED CONDITIONS}

The frequency of this category in the population is maintained by recurrent mutation. Although the present calculations are limited to serious conditions, these still have a spectrum of severity. ${ }^{21}$ Thus, among the dominants are included conditions of early manifestation, such as retinoblastoma and achondroplasia, as well as those of late onset, such as Huntington's chorea and monogenic hypercholesterolaemia associated with ischaemic heart disease. The sex-linked conditions include Duchenne type X-linked muscular dystrophy and classical haemophilia. Taking this group as a whole, it is thought from results of the Northern Ireland population survey ${ }^{22}$ that the first generation incidence of the mutations concerned is about one-fifth of the equilibrium incidence, ${ }^{23}$ that is their average persistence is about five generations.

An overall population frequency of $1 \%$ harmful dominant and sex-linked conditions was estimated by UNSCEAR ${ }^{24}$ on the basis of the Northern Ireland survey. ${ }^{22}$ In contrast, a more recent British Columbia survey of conditions expressed at birth and in early childhood suggested that the frequency was only about one-tenth of this. ${ }^{25}$ However, the late onset of many dominants, as shown by epidemiological analysis of a number of specific conditions, ${ }^{21}$ indicates that the true incidence may be as high as $1 \%$ when future recognition of further simple dominant disorders is also taken into account. This figure is used in these calculations and also by UNSCEAR. ${ }^{2}$

Given an equilibrium frequency of $1 \%$ and a doubling dose of $100 \mathrm{rem}$, an extra 100 cases per generation of dominant and sex-linked conditions will be expected at equilibrium after 1 million manrem per generation. This is also the total number of extra cases to be expected in all subsequent generations after 1 million man-rem to a single generation. With an average persistence of 5 generations, onefifth of these, that is 20 cases, will be manifest in the first generation and one-fifth of the remaining 80 , or 16 cases, in the second generation after exposure (table).

\section{DOMINANTS OF INCOMPLETE PENETRANCE}

Among the common congenital malformations and constitutional disorders there is believed to be a fraction that is mutationally maintained. These include dominants of incomplete penetrance, as well as some multifactorial conditions. The incomplete penetrance may be because of either genetic or environmental factors. If the penetrance is low the gene frequency is correspondingly higher. Selection will, of course, act only on cases where the condition becomes manifest. It is believed that, on average, about $10 \%$ of the new mutants will become manifest per generation. ${ }^{23}$

These two categories of genetic damage are very difficult to study and their birth frequency in the population cannot be determined with any degree of assurance. However, for radiation protection purposes a quantitative estimate is necessary, and it was felt that the number of extra cases at equilibrium after a parental dose of 1 million man-rem could be taken as the sum of the equilibrium values of the categories described above (unbalanced translocations, aneuploid conditions, and simple dominants), that is $100+30+30=160$, of which $10 \%$ (16) would become manifest in the first generation after a single exposure and 14 in the second. 
Selby and Selby ${ }^{26}$ have made detailed studies of skeletal anomalies in offspring and later generations of male mice given spermatogonial $\gamma$-irradiation. Many of these dominant mutations showed incomplete penetrance for some or all of their effects and could be regarded as models for similar irregularly inherited human conditions. The authors concluded that an important fraction of these conditions were maintained by mutation pressure rather than by balanced selection.

It is recognised that the approach to equilibrium of dominants of late onset and of incomplete penetrance might be slowed by genetic counselling and, in the future, by prenatal diagnosis and selective abortion. For instance, if effective genetic counselling were introduced for Huntington's chorea, the mean survival time of each mutant might be reduced from ten to two generations. The equilibrium birth frequency in north-west Europe would then be reduced from $5 \times 10^{-4}$ to $10^{-4}$ (C O Carter, 1976, personal communication).

\section{MULTIFACTORIAL CONDITIONS}

Occasional pedigrees are seen which suggest a dominant or irregularly dominant mode of inheritance of what are otherwise regarded as multifactorial conditions; these have been dealt with above. Most of the remaining cases seem to be maintained at their present frequencies through some mechanism of stabilising selection rather than mutation. The observed incidence of such a disorder in a given population is characterised by a relatively high frequency, a non-dominant pattern of inheritance, and a familial pattern of incidence (twins, sibs, cousins) indicating multifactorial inheritance. If it is assumed that the frequencies are dependent upon mutation, it becomes necessary to postulate improbably high spontaneous mutation frequencies for a significant fraction of the genome.

Since the frequencies are believed to be maintained by selection, an increase in the mutation rate is not taken to influence the prevalence of the condition. Also, the frequencies and activities of the various alleles of the several genes involved in any one condition are not known.

Examples of such conditions are most cases of cleft lip and cleft palate, as well as many other congenital malformations, ${ }^{27}$ pyloric stenosis, diabetes, and schizophrenia. ${ }^{28}$

\section{RECESSIVES}

In earlier risk estimates, this class of mutation has been regarded as relatively important because, mainly on the basis of findings with Drosophila, it was thought that recessives would show a 3 to $5 \%$ reduction in fitness in heterozygotes. However, most of the known heterozygotes for human metabolic diseases seem to suffer no adverse effects. In $\stackrel{\overparen{D}}{?}$ addition, induced recessive lethal conditions in the $\overrightarrow{\vec{H}}$ mouse generally fail to show any signs of heterozygous disadvantage, ${ }^{29}$ although a number of $\frac{}{C}$ conditions in the mouse with easily visible hetero- $\frac{\bar{c}}{\omega}$ zygous effects are known to be recessive lethals. ${ }^{30} \frac{\bar{\sigma}}{\widehat{D}}$ It is felt that human mutant alleles with characteristic- $\varrho$ ally $5 \%$ or higher heterozygous effect would be classified as dominants with incomplete penetrance. $\vec{O}$

On the other hand, some alleles which have deleterious effects in the homozygous condition, and $\vec{\omega}$ are therefore classed as recessive, may have some heterozygous advantage. These are not maintained in the population by recurrent mutation, as dis- $\vec{V}$ cussed above, so can be disregarded.

Newly induced recessive mutations with little or $\vec{G}$ no heterozygous effect may be expressed in homo- 0 zygous condition in later generations. The probability of a newly induced recessive mutation pairing up $\vec{T}$ with a previously existing mutant allele at the same $\mathbb{D}$ locus, so that the deleterious condition is expressed already in the first generation after exposure, is regarded as negligibly low. In general, homozygous $\vec{\bullet}$ effects of induced recessives will be spread over $\stackrel{\infty}{\circ}$ hundreds of generations, with a very slow attainment of equilibrium. In view of the diagnostic techniques that can be foreseen today, one would expect that within a few generations' time identification of recessive alleles of genetic ill health will be possible $\stackrel{\varrho}{\approx}$ in the heterozygote or prenatally in the homozygote, $\stackrel{\mathbb{2}}{2}$ with corresponding reduction in severity through $\overrightarrow{\vec{O}}$ genetic counselling and therapeutic abortion. It would $\frac{3}{3}$ be unrealistic to assume constant levels of knowledge in clinical genetics or constant reproduction patterns over periods of many centuries.

For the above reasons, and in the context of radiation protection, it was thought that true reces- $\dot{0}$ sives would probably not contribute significantly to the extra mutation load following low level radiation exposure; therefore no value has been entered for this category in the table. This is in keeping with the $O$ findings of the BEIR Committee ${ }^{23}$ and UNSCEAR ${ }^{2}$ has since followed a similar line.

The evaluation of recessive mutational effects is very difficult and, not surprisingly, members of the o Task Group were not unanimous in their views on $N$ this subject. Two corresponding members have stated that "the risk from 'nominal' recessive dis- 0 orders, although largely concealed for many generations, may be a far graver problem than all other hazards combined, especially if these so-called $\stackrel{0}{\rightarrow}$ recessives have any significant effects in the hetero- $T$ zygotes. However, in the present state of our knowledge this aspect of the risk problem is extremely difficult to quantify" (J H Edwards and J V Neel, 1976, personal communication). 


\section{Conclusion}

As the table shows, the total genetic risk of serious ill health after 1 million man-rem to parents adds up to 125 cases in the first two generations after exposure and 320 cases at equilibrium, if the same dose is given in every generation to a stable population. This latter figure will also be the number of extra cases in all succeeding generations from a single generation's dose of 1 million man-rem. Estimates are given for the first two generations after exposure because these generations will be of predominant interest to the radiation worker in his or her own lifetime. It should be emphasised that these estimates apply to genetically significant doses, so have to be modified when, for instance, some part of a lifetime's occupational exposure is given after the age of reproduction. ${ }^{31}$ The estimate of 89 extra cases of serious genetic damage in the first generation after 1 million man-rem is not far removed from the corresponding estimate in UNSCEAR $^{2}$ with use of the doubling dose method, namely 63 cases per million per rad of low LET radiation given at low doses and dose rates. It hardly needs to be stressed, however, that these and other current estimates all depend on a large number of assumptions, many of which are common to the various estimates, and any of which may prove to be unfounded. Thus, although this risk estimate is regarded as a realistic one, without built-in safety factors, it undoubtedly has wide confidence limits.

These estimates can be placed in the context of actual medical exposures by use of the finding of Taylor and $\mathrm{Webb}^{32}$ that the annual genetically significant dose from medical irradiation received by members of the United Kingdom population is about $100 \mu \mathrm{Sv}$ (10 millirem) on average. Thus, in a generation of 30 years, a genetically significant medical dose of 1 million man-rem would be expected to accumulate in a population of $3 \cdot 3$ million persons, with the hereditary consequences predicted. It should be emphasised that this would be mainly a dose to patients rather than an occupational dose to medical personnel.

\section{References}

1 ICRP. Recommendations of the International Commission on Radiological Protection (ICRP publication 26). Ann ICRP 1977;1 :No 3.

2 UNSCEAR. Sources and effects of ionizing radiation. New York: United Nations, 1977.

3 Sankaranarayanan K. Evaluation and re-evaluation of genetic radiation hazards in man. III. Other relevant data and risk assessment. Mutat Res 1976;35:387-414.

4 Searle AG. Use of doubling doses for the estimation of genetic risks. Proc I European Symposium on RadEquivalence. CEC Series on Radiological Protection, 1977,EUR5725e:133-45.
5 Searle AG. Mutation induction in mice. Adv Radiat Bio 1974;4:131-207.

- Pomerantzeva MD, Ramaiya LK, Ivanov VN. Mutagenic effects of different types of radiation on germ-cells of male mice. VII. The frequency of reciprocal translocations in spermatogonia subjected to different doses of gammairradiation. Genetika $1972 ; 8(12): 128-34$.

7 Evans HJ, Buckton KE, Hamilton GE, Carothers A. Radiation induced chromosome aberrations in nucleardockyard workers. Nature 1979;277:531-3.

8 Ford CE, Evans EP, Searle AG. Failure of irradiation to induce Robertsonian translocations in germ-cells of male mice. In: Conference on mutations, their origin, nature and potential relevance to genetic risk in man. Bonn: Deutsche Forschungsgemeinschaft, 1977:102-8.

- Russell LB. Numerical sex-chromosome anomalies in mammals: their spontaneous occurrence and use in mutagenesis studies. In: Hollaender A, ed. Chemical mutagens. vol 4. New York: Plenum, 1976:55-91.

10 Brewen JG, Preston RJ, Gengozian N. Analysis of $x$-ray induced chromosomal translocations in human and marmoset spermatogonial stem cells. Nature 1975;253: 468-70.

11 Searle AG, Beechey CV, Corp MJ, Papworth DG. A doserate effect on translocation induction by $\mathrm{X}$-irradiation of mouse spermatogonia. Mutat Res 1972;15:89-91.

12 Searle AG, Evans EP, Ford CE, West BJ. Studies on the induction of translocations in mouse spermatogonia. I. The effect of dose-rate. Mutat Res 1968;6:427-36.

13 Ford CE, Searle AG, Evans EP, West BJ. Differential transmission of translocations induced in spermatogonia of mice by irradiation. Cytogenetics $1969 ; 8: 447-70$.

14 UNSCEAR. Ionizing radiation: levels and effects. vol II. Effects. New York: United Nations, 1972.

15 Searle AG, Beechey CV. Cytogenetic effects of $x$-rays and fission neutrons in female mice. Mutat Res 1974;24: 171-86.

16 Krishna M, Generoso WN. $X$-ray induction of heritable translocations in mouse dictyate oocytes. Genetics 1977; 86 :s36-7.

17 Russell WL. Mutation frequencies in female mice and the estimation of genetic hazards of radiation in women. Proc Nat Acad Sci USA 1977;74:3523-7.

18 Searle AG. Chromosome damage and risk assessment. In: Human genetics. Proc IV Int Cong Hum Genet Paris 1971. Amsterdam: Excerpta Medica, 1972:58-66.

19 Russell LB, Montgomery CS. The incidence of sexchromosome anomalies following irradiation of mouse spermatogonia with single or fractionated doses of $x$-rays. Mutat Res 1974;25:367-76.

20 Searle AG. Nature and consequences of induced chromosome damage in mammals. Genetics $1974 ; 78: 173-86$.

21 Carter CO. Monogenic disorders. J Med Genet 1977;14: 316-20.

22 Stevenson A. The load of hereditary defects in human populations. Radiat Res Suppl 1959;1:306-25.

23 BEIR Report. The effects on populations of exposure to low levels of ionizing radiation. Washington DC: National Academy of Sciences, National Research Council, 1972.

24 UNSCEAR. Report of the United Nations Scientific Committee on the effects of atomic radiation. General Assembly Suppl 16 (A/5216). New York: United Nations, 1962.

25 Trimble BK, Doughty JH. The amount of hereditary disease in human populations. Ann Hum Genet 1974;38: 199-223.

${ }^{26}$ Selby PB, Selby PR. Gamma-ray-induced dominant mutations that cause skeletal abnormalities in mice. Mutat Res 1977;43:357-75. 
27 Leck I. Congenital malformations and childhood neoplasms. J Med Genet 1977;14:321-6.

28 Shields J. The major psychoses. J Med Genet 1977;14: 327-9.

29 Lüning KG. Dominant effects of recessive lethals in mice. II. Viability and mating ability. Mutat Res 1969;8: 573-80.

30 Green MC. Mutant genes and linkages. In: Green EL, ed. Biology of the laboratory mouse. New York: McGraw-Hill, 1966:87-150.
31 ICRP. Problems involved in developing an index of harm. (ICRP publication 27). Ann ICRP 1977;1:No 4.

32 Taylor FE, Webb GAM. Radiation exposure of the $U K \overrightarrow{\bar{B}}$ population. National Radiological Protection Board report R-77. London: HMSO, 1978.

Requests for reprints to Dr A G Searle, MRC Radiobiology Unit, Harwell, Didcot, Oxon OX11 ORD. 